\title{
Study on incidences of electrolyte disorders among children with dehydration
}

\author{
Chakravarthi G.K. ${ }^{1}$, R. Praveen Kumar ${ }^{2}$ \\ ${ }^{1}$ Dr. G. Kalyan Chakravarthi, Associate Professor, ${ }^{2}$ Dr. R. Praveen Kumar, Assistant Professor; both authors are affiliated \\ with Department of Paediatrics, GSL Medical College \& General Hospital, Rajahmundry, Andhra Pradesh, India
}

Corresponding Author: Dr. R Praveen Kumar, Assistant Professor, Department of Paediatrics, GSL Medical College \& General Hospital, Rajahmundry, Andhra Pradesh, India, E-mail: ddguru2019@gmail.com

\begin{abstract}
Background: Electrolyte abnormalities are common in children with diarrhoea. It may remain unrecognized and result in mortality and morbidity. Timely recognition, a high index of suspicion and thorough understanding of common electrolyte abnormalities is necessary to ensure their correction. The present work was undertaken to determine the incidence and clinical importance of Hypokalemia, hypernatraemia, Hyponatremia and Hypernatremia in children with acute diarrheal diseases with dehydration. Method: The present prospective study was conducted at Department of Paediatrics, GSL Medical College \& General Hospital, Rajahmundry from 2015 to 2017.Consecutive Patients attending OPD and inpatients in view of acute diarrhea between 1month and 5years of age were included in the study. A detailed history from the patients with acute gastroenteritis of age 1 month to 5 years was taken. Result: The incidence of Acute diarrhoea was greater in males (54.6\%\%) compared to females (45.4\%). Severe Dehydration was present in $39.1 \%$ cases and some dehydration was present in $60.8 \%$ cases. Hyponatremic dehydration was present in $33 \%$ cases, Isonatremic dehydration in $59.8 \%$ and hypernatremic dehydration in $7.2 \%$ cases. Mean sodium levels being $134.97 \mathrm{mmol} / \mathrm{l}$. Hypokalemia was present in $44.3 \%$ cases, normal levels in 51.6\% and Hyperkalemia in $4.2 \%$ cases. Mean potassium levels being $3.62 \mathrm{mmol} / 1$. Conclusion: Like any other electrolyte abnormalities, which occurs in conditions other than diarhoea, are basically asymptomatic \& does not require aggressive correction of electrolytes. They do very well with ORS \& fluid correction as recommended by W.H.O.
\end{abstract}

Keywords: Children, Diarrhoea, Sodium level, Potassium level

\section{Introduction}

Almost 1.731 billion episodes of diarrhoea occurred in 2010 in children younger than 5 yr. of age in developing countries, with more than $80 \%$ of the episodes occurring in Africa and South Asia $(50.5 \%$ and $32.5 \%$, respectively) and 36 million of the total episodes progress to severe episodes [1].

Global mortality may be declining rapidly, but the overall incidence of diarrhoea has only declined from 3.4 to approximately 2.9 episodes per child-year in the past 2 decades, and it is estimated to account for 23 million childhood disability-adjusted life year [1]. Of India's more than 2.3 million annual deaths among children, about 334000 are attributable to diarrhoeal diseases [2].

Manuscript received: $28^{\text {th }}$ June 2019

Reviewed: $7^{\text {th }}$ July 2019

Author Corrected: $15^{\text {th }}$ July 2019

Accepted for Publication: $20^{\text {th }}$ July 2019
In India, acute diarrhoeal disease accounts for about 8\% of deaths in under-5 years age group. During the year 2014, about 11.6 million cases with 1,323 deaths were reported in India [3]. The high incidence of diarrhoeal diseases in developing countries is related to undernutrition, increased vulnerability to infections, poor education, socio-economic status and the unfortunate trend of early breast milk substitutes. Decreasing trend of exclusive breast feeding and faulty practices of bottle-feeding plays an important role. The main cause of death in acute diarrhoea is dehydration, which results from the loss of fluid and electrolytes in diarrheal stools.

The clinical manifestations of acute diarrhoea are related to the severity of water deficit and the type of electrolyte disturbances. Often laboratory facilities are not available or, even if available; there is a 


\section{Original Research Article}

considerable time lag in obtaining the results. Consequently, clinical recognition of water and electrolyte disturbances becomes important, particularly Hyponatremic dehydration, due to its serious neurological consequences.

A study conducted in 2010 in Dhaka Shishu hospital showed that electrolyte disturbances in Acute Gastroenteritis was associated with increased morbidity, with hyponatremic dehy-dration in $15 \%$ cases[4].

A study by Molat et al. showed that increasing severity of hypernatremia leads to increase in mortality rate and is associated with significant difference in Denver Developmental Screening II test results [5].

Electrolyte abnormalities are common in children with diarrhoea. It mayremain unrecognized and result in mortality and morbidity. Timely recognition, a high index of suspicion and thorough understanding of common electrolyte abnormalities is necessary to ensure their correction.

Different studies have shown different incidences of electrolyte disorders among children with dehydration. The present work was undertaken to study the common electrolyte abnormalities in diarrhoea and its impact on the mortality.

Objectives: To determine the incidence and clinical importance of Hypokalemia, hypernatraemia, Hyponatremia and Hypernatremia in children with acute diarrheal diseases with dehydration.

\section{Material and Methods}

Type of study: Prospective study

Study setting: Department of Paediatrics, GSL Medical College \& General Hospital, Rajahmundry.

Study period: 2015 to 2017 .

Study group: Consecutive Patients attending OPD and inpatients in view of acute diarrhea between 1 month and 5years of age.

\section{Inclusion criteria}

1. Children between 1 month and 5years of age (with acute gastroenteritis)

2. Large frequent stools ( 3 or $>$ )

3 . Excessive vomiting ( 4 or $>$ )

4. Some \& severe dehydration.

\section{Exclusion criteria}

1. Parenteral diarrhea.

2. Gastroenteritis more than 14 days

3. Severe Acute Malnutrition.

Method of collection: A detailed history from the patients with acute gastroenteritis of age 1 month to 5 years was taken. The procedure of the study was explained \& required consent for the study was taken.

Detailed clinical examination was done to look for thirsty, irritability, pinched look, sunken eyes, dry inner side of cheeks, abdominal distention, deep and rapid breathing, weak and thready pulse, falling blood pressure, reduced quantity of urine according to WHO dehydration assessment scale.

\section{Laboratory investigations}

1. Basal Hematological and Biochemical investigations were done in all patients, including hemoglobin, total and differential white cell counts, platelets \& peripheral smear examination

2. Basal blood urea nitrogen and basal random blood sugar was done in all patients.

3. Serum electrolytes were determined at ' 0 ' hour (admission) and once between 24 to 48 hours(post hydration)

\section{Definitions}

\section{Serum Sodium Levels}

- Normal Sodium levels- 135-145 mmol/1;

- Hyponatremia $<135 \mathrm{mmol} / \mathrm{l}$;

- Hypernatremia $>145 \mathrm{mmol} / \mathrm{l}$.

\section{Serum Potassium Levels}

- Normal Potassium levels-3.5-5.5 mmol/l;

- Hypokalemia<3.5 mmol/l;

- Hyerkalemia $>5.5 \mathrm{mmol} / \mathrm{l}$.

Fluid therapy: This was designed to correct dehydration, electrolyte imbalance, acidosis and maintain urinary output.

Statistical analysis: Descriptive statistics such as mean, SD and percentage was used to present the data. Data was analysed by using software SPSS v20.0. Microsoft excel was used to construct tables and graphs. 


\section{Results}

Table-1: Distribution of serum sodium levels in children

\begin{tabular}{|c|c|c|}
\hline Serum Sodium Levels & Frequency & Percentage \\
\hline Hyponatremia(135) & 32 & 33 \\
\hline Isonatremia(135-145) & 58 & 59.8 \\
\hline Hypernatremia(>145) & 7 & 7.2 \\
\hline Total & $\mathbf{9 7}$ & $\mathbf{1 0 0}$ \\
\hline
\end{tabular}

In this present study out of 97 children studied, 32(33\%) children had hyponatremic dehydration, 58(59.8\%) children had isonatremic dehydration and 7(7.2\%) had hypernatremic dehydration (Table-1).

Table-2: Serum sodium levels in different age groups of children

\begin{tabular}{|c|c|c|c|c|}
\hline \multirow{2}{*}{$\begin{array}{c}\text { Age } \\
(\text { years })\end{array}$} & \multirow{2}{*}{ Sex } & Serum Sodium (MMOL/L) \\
\cline { 3 - 5 } & & Hyponatremia (135) & $\begin{array}{c}\text { Isonatremia } \\
(\mathbf{1 3 5 - 1 4 5})\end{array}$ & Hypernatremia (>145) \\
\hline \multirow{2}{*}{$<1$} & $\mathrm{M}$ & $11(11.3)$ & $14(14.4)$ & $2(2.1)$ \\
\cline { 2 - 5 } & $\mathrm{F}$ & $8(8.2)$ & $12(12.4)$ & $2(2.1)$ \\
\hline \multirow{2}{*}{$1-2}$. & $\mathrm{M}$ & $4(4.1)$ & $5(5.2)$ & $0(0)$ \\
\cline { 2 - 5 } & $\mathrm{F}$ & $3(3.1)$ & $4(4.1)$ & $1(1)$ \\
\hline \multirow{2}{*}{$3-5}$. & $\mathrm{M}$ & $4(4.1)$ & $11(11.3)$ & $0(0)$ \\
\cline { 2 - 5 } & $\mathrm{F}$ & $2(2.1)$ & $12(12.4)$ & $\mathbf{7 ( 7 . 2 )}$ \\
\hline
\end{tabular}

In the present study, the incidence of hyponatermic dehydration is almost all similar in both age groups (in $<1$ year and 3-5 years) (Table-2).

Table-3: Serum potassium levels in children

\begin{tabular}{|c|c|c|}
\hline Serum Potassium(MMOL/L) & Frequency & Percentage \\
\hline Hypokalemia(<3.5) & 43 & 44.3 \\
\hline Isokalemia(3.5-5.5) & 50 & 51.6 \\
\hline Hyerkalemia(.5.5) & 4 & 4.2 \\
\hline
\end{tabular}

In the present study, out of 97 children, 43(44.3\%) children had hypokalemia, 50(51.6\%) had normal levels and $4(4.2 \%)$ had hyperkaemia (Table-3).

Table-4: Serum Potassium Levels in Different Age Groups

\begin{tabular}{|c|c|c|c|c|}
\hline \multirow{2}{*}{$\begin{array}{c}\text { Age } \\
(\text { YRS })\end{array}$} & \multirow{2}{*}{ Sex } & \multicolumn{3}{|c|}{ Serum Potassium (MMOL/L) } \\
\cline { 3 - 5 } & & $\begin{array}{c}\text { Hypokalemia } \\
(<3.5)(\%)\end{array}$ & Isokalemia (3.5-5.5)(\%) & Hyperkalemia (>5.5)(\%) \\
\hline \multirow{3}{*}{$<1$} & $\mathrm{M}$ & $12(12.3)$ & $14(14.5)$ & $1(1)$ \\
\cline { 2 - 5 } & $\mathrm{F}$ & $9(9.3)$ & $11(11.3)$ & $2(2.1)$ \\
\hline \multirow{2}{*}{$1-2}$. & $\mathrm{M}$ & $6(6.2)$ & $3(3.1)$ & $0(0)$ \\
\cline { 2 - 5 } & $\mathrm{F}$ & $3(3.1)$ & $4(4.1)$ & $0(0)$ \\
\hline \multirow{2}{*}{$3-5}$. & $\mathrm{M}$ & $8(8.2)$ & $9(9.3)$ & $0(0)$ \\
\cline { 2 - 5 } & F & $5(5.2)$ & $9(9.3)$ & $\mathbf{4 ( 4 . 2 )}$ \\
\hline
\end{tabular}

The incidence of hypokalemia is highest in children less than 1 year (21.6\%) (Table-4). 
Table-5: Frequency of type of dyselectrolytemia in children

\begin{tabular}{|l|c|c|}
\hline Type of Dyselectrolytemia & Frequency & Percentage \\
\hline Isolated hyponatremia & 8 & 17.2 \\
\hline Isolated hypokalemia & 17 & 3.1 \\
\hline Isolated hypernatremia & 3 & 0 \\
\hline Isolated hyperkalemia & 0 & 23.7 \\
\hline Hyponatremia+hypokalemia & 23 & 2.1 \\
\hline Hyponatremia+hyperkalemia & 2 & 3.1 \\
\hline Hypernatremia+hypokalemia & 3 & 2.1 \\
\hline Hypernatremia+hyperkalemia & 2 & $\mathbf{1 0 0}$ \\
\hline Total & $\mathbf{9 7}$ & \\
\hline
\end{tabular}

In the present study, out of 97 children, 58(59.8\%) children had either isolated or mixed dyslectrolemia and 39(40.2\%) had dehydration without sodium or potassium abnormalities. Majority of the children with dyselectrolytemia had both hyponatremia and hypokalemia 23(23.7\%)followed by isolated hypokalemia17(17.5\%)(Table-5).

In the present study, out of 97 children $3(3.1 \%)$ children died and 94 (96.9\%) children survived. $3(2.1 \%)$ children died had both hyponatremia and hypokalemia. 1 (1\%) had hypernatremia and hyperkalemia.All 3 (3.1\%) children who died of electrolyte abnormality also had high levels of blood urea and serum creatinine.

\section{Discussion}

Age: The most common age group in the present study was age less than 1 year $(50.51 \%)$ followed by $3-5$ years $(31.95 \%)$.

M M Okposio et.al study found similar age distribution with present study. The study conducted in 185 children who are less than 5 years of age of which 103(55.7\%) falls under an age of $<1$ year and $82(44.3 \%)$ above 1 year [6].

Conway et.al study included 1148 children younger than 16 years admitted to a subregional infectious disease hospital with a diagnosis of gastroenteritis over a 1 year period. Of the admitted children, 55\% $(635 / 1148)$ were younger than 1 year while $5 \%$ were over 5 years of age [7].

Habibullah babar et. al conducted similar study, in which majority of patients admitted were below 24 months of age i.e., 114(65.5\%) [8]. Mirza Sultan Ahmad, et.al. According to age, 11 (10.6\%) patients were below one month, $48(46.1 \%)$ were between 1 month and 11 months, 32 (30.8\%) were between 1 year and 4 years and 11 months, and $13(12.5 \%)$ were 5 years [9]. Srivastava et.al conducted a study, 110 hospitalized children up to 3 years of age suffering from diarrhoea were investigated. The peak of admission due to diarrhoea was in the month of June. Cases aged 0-12 months constituted $72.8 \%$ of the total number of cases [10]. Shah GS et al study showed Majority (70\%) of patients were below 2 years of age [11].

Sex: In this study, total 97 children where studied, male children $53(54.6 \%)$ outnumber female children $44(45.4 \%)$, with a male to female ratio of 1.2:1. Habibullah Babar et.al conducted similar study, in which majority of patients admitted were males 112 (64.4\%) and Female patients were 62(35.6) [8].Acute diarrheal disease was more common in boys than girls with the ratio of 1.2:1, a finding which is similar to that reported by Srivastava et al [10] and Behera et al [12]. Rebecca Oketcho et.al showed that nearly all children (99.5\%) resided in Morogoro and there were more male children $(57.9 \%)$ than female children $(42.1 \%)$ [13]. There were $37(65 \%)$ males and 20(35\%) females according to Shah GS et al study [11]. M M Okposio et.al study observed similar findings in age distribution, A total of 185 children met the inclusion criteria out of the 302 admitted for diarrhoeal disease during the study period. Of these, $107(57.8 \%)$ were males and 78 $(42.2 \%)$ were females with a male female ratio of $1.4: 1$ [6].

Dehydration: In this present study, out of 97 children studied, 59(60.8\%) children had some dehydration and $38(39.2 \%)$ children had severe dehydration. 
Children below 1 year had highest incidence of severe dehydration, 21 out of 49 (42.9\%), followed by similar incidence of severe dehydration in both $1-2$ years (6 out of 17 children) $35.3 \%$ and $3-5$ years (11 out of 31 children) $35.5 \%$. In a study by JA Begum et al, out of 100 children found 57 children found to have sighs of dehydration dehydration [4]. Dastidar RG et.al study shows $83 \%$ (166) of the children had some dehydration and $34(17 \%)$ children had severe dehydration [14].

Mittal et.al has reported 50.52\% of moderate dehydration and $21.95 \%$ severe dehydration in their study [15].

Wathen et al study shows, out of 71 children studied, 55 children had some dehydration and 16 with severe dehydration [16].

Gauchan E et.al study shows similarities with present study, out of 168 patients, Severe dehydration was seen in $22(11.7 \%) ; 123$ children $(65.4 \%)$ had Some dehydration while 43(22.9\%) had No dehydration [17].

Serum Sodium levels: In this present study out of 97 children studied, 32(33\%) children had hyponatremic dehydration, 58 (59.8\%) children had isonatremic dehydration and $7(7.2 \%)$ had hypernatremic dehydration.

In the present study, the incidence of hyponatermic dehydration is almost all similar in both age groups (in< 1 year and 3-5 years). M M Okposio et.al study shows correlation with present study, Dehydration was hyponatraemic in $112(60.5 \%)$ children, hypernatraemic in $8(4.3 \%)$ and isonatraemic in $65(35.1 \%)$ [6].

Gauchan E et.al study shows Dehydration was isonatremic in $137(72.9 \%)$, hypernatraemic in 30 $(16 \%)$ and hyponatraemic in $21(11.2 \%)$ [17].

Pizzoti et al [18] study, found hyponatremia 34\% of admitted patients and 5.7\% in Habibullah Barbar et.al study [8]. Isolated hypernatremia was $2.9 \%$, in a study of Jenkins and Ansari study found it $<1 \%$ of their cases [19]. It is because of most fluid in diarrhoea lost with a lower sodium concentration.

The incidence of hypernatremia was $15.7 \%$ in a study by Subba Gangaraj et al.[20], Shah GS et al study showed that, major electrolyte disturbances noted were hyponatremia (56\%), which was either isolated $(26 \%)$ or associated with hypokalemia (26\%) and about $10 \%$ patient had hypernatremia [11]
Original Research Article

The study by Shah et al showed that $56 \%$ of cases admitted with diarrhea and dehydration had hyponatremia, while hypernatremia was present in $10 \%$ cases [11].

A clinical and biochemical study by K. R. Purohit et al of 100 cases of acute diarrhoea in infancy was done. 75 cases each showed low serum values of sodium Electrolyte disturbances in acute diarrhea [21].

Alireza Soleimani et.al study shows, at the time of admission, out of 121 patients, 82 patients $(67.8 \%)$ had hyponatremia (plasma $\mathrm{Na}<137 \mathrm{mEq} / \mathrm{L}$ ) only 7 patients $(5.7 \%)$ developed hypernatremia (plasma $\mathrm{Na}>143$ $\mathrm{mEq} / \mathrm{L}$ ) and rest 32 patients (26.5) had isonatremia [22].

Serum Potassium levels: In the present study, out of 97 children, 43(44.3\%) children had hypokalemia, $50(51.6 \%)$ had normal levels and 4(4.2\%) had hyperkaemia. The incidence of hypokalemia is highest in children less than 1 year $(21.6 \%)$.

Shah GS et al study showed The second common abnormality was hypokalemia (46\%) which was again either isolated $(14 \%)$ or associated with hyponatremia (26\%). and about 3\% had hyperkalemia [11]. In Habibullah babar et. al study, the common abnormality was isolated hypokalemia $43.7 \%$ in the present study followed by mixed hyponatremia plus hypokalemia in $8.6 \%$ of patients [8]. In Dastidar RG et. al study, 170 children $(85 \%)$ had Normokalemia and 30 cases $(15 \%)$ had Hypokalemia and none of the cases had hyperkalemia. 6 cases of hyponatremia had associated hypokalemia [14].

Gauchan E et. alstudy shows, out of 188 children studied, 14 patients had hypokalemia, 168 had normal serum potassium levels and 6 had hyperkalemia [17]. Subba Gangaraj et al showed, majority of the cases $51.53 \%$ were having hypokalemia, $31.57 \%$ cases had hyponatremia, $15.7 \%$ had hypernatremia [20].

Alireza Soleimani et. alstudy showed, 41 patients $(33.88 \%)$ had hypokalemia on admission. They had plasma potassium less than $3.5 \mathrm{mEq} / \mathrm{L}$, and only three persons $(2.4 \%)$ were diagnosed with hyperkalemia.

Furthermore, $23(56.1 \%)$ of patients with mild hypokalemia were affected by severe form $(3<$ plasma $\mathrm{K}<3.5 \mathrm{mEq} / \mathrm{L})$ and 18 persons $(43.9 \%)$ suffered from its severe form (plasma $\mathrm{K}<3 \mathrm{mEq} / \mathrm{L}$ ). The low potassium level was more prevalent than the severe hyponatremia $(43.9 \%$ vs. $1.4 \%)[22]$. 


\section{Original Research Article}

Types of dyselectrolytemia: In the present study, out of 97 children, 58(59.8\%) children had either isolated or mixed dyslectrolemia and $39(40.2 \%)$ had dehydration without sodium or potassium abnormalities.

Majority of the children with dyselectrolytemia had both hyponatremia and hypokalemia 23(23.7\%) followed by isolated hypokalemia17(17.5\%). The present study had similarities in type of dyselectrolemia with the studies done by Habibullah Barbar et.al [8] and Shah GS [11].

Case fatality rate: In the present study, out of 97 children $3(3.1 \%)$ children died and $94(96.9 \%)$ children survived. 3 (2.1\%) children died had both hyponatremia and hypokalemia. 1 (1\%) had hypernatremia and hyperkalemia. All $3(3.1 \%)$ children who died of electrolyte abnormality also had high levels of blood urea and serum creatinine. In a study by Shan GS showed, out of 46 patients with abnormal electrolyte pattern 5 died while there was no death amongst 11 patients with normal electrolytes [11].

However, statistically significant mortality was observed in patients presenting with either hyponatremia or hypokalemia as compared to the group with normal electrolytes.

Limitation: The present study was based on a small sample size. A larger study group is recommended to come to a very definite conclusion.

\section{Conclusion}

Hypokalemia is the most common electrolyte abnormality noted, followed by hyponatremia. Most of the patients with transient hyponatremia and transient hypokalemia, treated with ORS. These patients did not show classical signs \& symptoms of hyponatremia. \& hypokalemia.

Like any other electrolyte abnormalities which occurs in conditions other than diarhoea, are basically asymptomatic \& does not require aggressive correction of electrolytes. They do very well with ORS \& fluid correction as recommended by W.H.O.

\section{What the present study adds to existing knowledge?}

Literature on the incidences of electrolyte disorders among children with dehydration has shown different incidences rates which make a meaningful adding in existing literature by conducting the present study in the present study area to timely recognition and understanding of common electrolyte abnormalities.

\section{Author's contribution:}

Dr. G. Kalyan Chakravarthi: Concept and manuscript preparation.

Dr R. Praveen Kumar: Study Design and manuscript preparation.

Funding: Nil, Conflict of interest: None initiated, Perission from IRB: Yes

\section{Reference}

1. Acute Gastroenteritis in Children; Nelson's Textbook of paediatrics: 1st South-Asia edition, Chapter 340, Pg No: 1854.

2. Million Death Study Collaborators. Causes of neonatal and child mortality in India: a nationally representative mortality survey. The Lancet. 2010; 376(9755):1853-60.doi: 10.1016/S0140-6736(10) 61461-4

3. Govt of India (2014), National Health Profile 2013 (Jan-Dec), DGHS, Central Bureau of Health Intelligence, Ministry of Health and Family Welfare, New Delhi.

4. Begum J, Hoque M, Hussain M, Hasan M, Molla M. Impact of electrolyte disturbances in outcome of acute diarrhoea in children. Impact of electrolyte disturbances in outcome of acute diarrhoea in children. 2010; 26 (1): 36-40.

5. Bolat F, Oflaz MB, Güven AS, Özdemir G, Alaygut D, Dogan MT, Içagasoglu FD, Cevit Ö, Gültekin A. What Is the Safe Approach for Neonatal Hypernatremic Dehydration?: A Retrospective Study From a Neonatal Intensive Care Unit. Pediatric Emerg Care. 2013; 29 (7):808-13.doi: 10.1097/PEC.0b013e3182983bac.

6. Okposio MM, Onyiriuka AN, Abhulimhen-Iyoha BI, Point-of-Admission Serum Electrolyte Profile of Children less than Five Years Old with Dehydration due to Acute Diarrhoea, Trop Med Health. 2015;43(4);247252.doi: 10.2149/tmh.2015-29

7. Conway SP, Phillips RR, Panday S. Admission to hospital with gastroenteritis. Archives of disease in childhood. 1990;65(6):579-84. 
8.Barbar H,Sanaullah MR, Rahim M. Serum Electrolyte Disturbances in Acute Diarrhoea among Children Less Than 5 Years of Age, Pak J Med Health Sci. 2016; 10(4): 1231-1234.

9. Ahmad MS, Wahid A, Ahmad M, Mahboob N, Mehmood R. Prevalence of electrolyte disorders among cases of diarrhea with severe dehydration and correlation of electrolyte levels with age of the patients. J College Physician Surg: Pakistan: JCPSP.2016; 26(5):394-8.

10. Srivastava AK, Bhatnagar JK, Prasad BG, Sharma NL. A clinical aetiological study of diarrhoea in hospitalized children at Lucknow. Indian J Med Res. 1973;61(4):596-602.

11.Shah GS, Das BK, Kumar S, Singh MK, Bhandari GP. Acid base and electrolyte disturbance in diarrhoea. Kathmandu Univ Med J(KUMJ).2007;5(1):60-2.

12. Behera SK, Mohapatra SS, Kar S, Das D, Panda C. Incidence and mortality of hospitalized diarrhoea cases. Part III. Indian Pediat. 1980;17(7):607.

13. Oketcho R, Karimuribo ED, Nyaruhucha $\mathrm{CN}$, Taybali S. Epidemiological factors in admissions for diarrhoea in 6-60-month-old children admitted to Morogoro Regional Hospital, Tanzania. South Afri J Child Health. 2012;6(3):81-4.

14. Dastidar RG, Konar. A Study of Electrolyte Disturbances in a Child Presenting with Acute Gastroenteritis, with Special Emphasis on Hyponatremic Dehydration-A Hospital based Cross-Sectional Study. Pediatr Ther 2017;7:(2) 2-4.

\section{Original Research Article}

15. Mittal SK, Saxena S, Mundkur N, Srivastava G, Gupta S. Acute diarrhea in malnourished children. Clinical, biochemical and bacteriological profile. Indian pediatrics. 1980;17(3):247-54.

16. Wathen JE, MacKenzie T, Bothner JP. Usefulness of the serum electrolyte panel in the management of pediatric dehydration treated with intravenously administered fluids. Pediat. 2004;114(5):1227-34.

17. Gauchan E, Malla KK. Relationship of Renal Function Tests and Electrolyte Levels with Severity of Dehydration in Acute Diarrhea. J Nepal Health Res Coun. 2015;13(29):84-9.

18. Pizzotti NJ, Madi JC, Iamanaca AI, Seguro AC, Rocha AS. Hyponatremia: study of its epidemiology and mortality. Revista do Hospital das Clinicas. 1989;44(6):307-11.

19. Jenkins HR, Ansari BM. Management of gastroenteritis. Arch Dis Childhood. 1990;65(9):93941.doi: 10.1136/adc.65.9.939

20. Gangaraj S, Das G, Madhulata S. Electrolytes and blood sugar changes in severely acute malnourished children and its association with diarrhoea and vomiting. Int J Pharm Sci Invent. 2013;2(5):33-6.

21. Purohit KR, Jyotsna PS. Electrolyte disturbances in acute diarrhoea. Indian J Pediat. 1971;38(10):393-5.

22. Soleimani A, Foroozanfard F, Tamadon MR. Evaluation of water and electrolytes disorders in severe acute diarrhea patients treated by WHO protocol in eight large hospitals in Tehran; a nephrology viewpoint. JRenInjPreven.2017;6(2):109.doi:10.15171/jrip.2017.21

\section{How to cite this article?}

Chakravarthi G.K, R. Praveen Kumar. Study on incidences of electrolyte disorders among children with dehydration. Int J Pediatr Res. 2019;6(07):352-358.doi:10. 17511/ijpr.2019.i07.07 